\title{
Factors contributing to drug-resistant tuberculosis treatment outcome in five countries in the Eastern Europe and Central Asia region
}

\author{
Christian Auer ${ }^{1,2}$, Rais Mazitov ${ }^{3}$, Alisher Makhmudov ${ }^{4}$, Bobojon Pirmahmadzoda ${ }^{5}$, Alena Skrahina ${ }^{6}$, \\ Andrei Dobre ${ }^{7}$, Florence Sécula ${ }^{1,2}$, Xavier Bosch-Capblanch ${ }^{1,2}$, Martin van den Boom ${ }^{8}$, \\ Giovanni Battista Migliori", Nino Mdivani ${ }^{10}$, Mohammed A. Yassin ${ }^{10}$ \\ ${ }^{1}$ Swiss Tropical and Public Health Institute, Basel, Switzerland; ${ }^{2}$ University of Basel, Switzerland; ${ }^{3}$ Stop TB Partnership, \\ Geneva, Switzerland; ${ }^{4}$ Independent consultant, Tajikistan; ${ }^{5}$ The City Center for TB Protection in Dushanbe, Tajikistan; \\ ${ }^{6}$ Republican Scientific and Practical Centre for Pulmonology and TB, Minsk, Belarus; ${ }^{7}$ Romanian Angel Appeal \\ Foundation, Bucharest, Romania; ${ }^{8}$ World Health Organization, Regional Office for Europe, Copenhagen, Denmark; \\ ${ }^{9}$ World Health Organization Collaborating Centre for Tuberculosis and Lung Diseases, Mangeri Care and Research \\ Institute, IRCCS, Tradate, Italy; ${ }^{10}$ The Global Fund to Fight AIDS, Tuberculosis and Malaria, Geneva, Switzerland
}

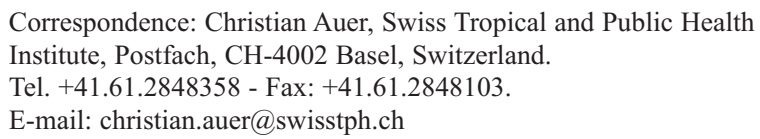

Key words: drug-resistant tuberculosis; treatment outcome; Eastern Europe; Central Asia; comprehensive support.

Acknowledgments: The support received from the "National TB Programmes" (NTPs) and the willingness of the patients and healthcare providers to interact with the research team is acknowledged. The statistical support of Jan Hattendorf is gratefully acknowledged. The authors are solely responsible for the views presented in the manuscript.

Contributions: CA, design of the work, fieldwork, analysis and interpretation of the data, drafting and revising the manuscript; RM, fieldwork in all five countries, analysis and interpretation of the data, revising the manuscript; AM, fieldwork, analysis and interpretation of the data; BP, $\mathrm{AS}, \mathrm{AD}$, facilitation of the field work, revising the manuscript; FS, fieldwork, analysis and interpretation of the data, revising the manuscript; XBC, design of the work, analysis and interpretation of the data; MvdB, NM, conception of the work, drafting and revising the manuscript; GBM, drafting and revising the manuscript; MY, conception and design of the work, interpretation of the data, drafting and revising the manuscript. All authors read and approved of the manuscript submitted here and agreed to be accountable for the contents of this manuscript.

Conflict of interest: none declared.

Funding: The conduct of this study was made possible through a grant from the Global Fund (Contract Number: 20164355).

Conference presentation: An oral presentation on some findings of this study was given at the $49^{\text {th }}$ World Conference on Lung Health of the UNION in 2018, in The Hague (title: Characteristics of patients with drug-resistant TB in Eastern Europe/Central Asia and determinants of their treatment outcome).

Received for publication: 28 January 2020

Accepted for publication: 11 March 2020.

${ }^{\circ}$ Copyright: the Author(s), 2020

Licensee PAGEPress, Italy

Monaldi Archives for Chest Disease 2020; 90:1235

doi: 10.4081/monaldi.2020.1235

This article is distributed under the terms of the Creative Commons Attribution Noncommercial License (by-nc 4.0) which permits any noncommercial use, distribution, and reproduction in any medium, provided the original author(s) and source are credited.

\section{Abstract}

Drug-resistant tuberculosis (DR-TB) is a global challenge and a major contributor of death from anti-microbial resistance. With the main aim to determine factors contributing to treatment outcomes observed among DR-TB patients in the countries in Eastern Europe and Central Asia (EECA), a multi-method study was conducted in: Azerbaijan, Belarus, Romania, Tajikistan and Ukraine. Both quantitative and qualitative methodologies were used for data collection and analysis. The quantitative approaches included a desk review of documents related to the DR-TB responses and an analysis of clinical records of DR-TB patients in selected health facilities of the five countries. Qualitative methods included in-depth interviews with national TB programme (NTP) managers, other healthcare providers and nongovernmental organizations (NGOs) workers, as well as interviews and Focus Group Discussions (FGDs) with DR-TB patients. The desk review of 38 reports identified as the main challenges to address DR-TB financial and/or management issues and adverse events of the medicines. The most common recommendations related to treatment outcome focussed on general programme management, treatment regimen composition, clinical management and social support for the patients. In all the five countries the NTPs still have a vertical structure. Some integration into the primary health care system (PHC) already exists but further involvement of PHC facilities is feasible and recommended. Interviews with stakeholders indicated that alcoholism and homelessness and a lack of appropriate response to these issues remain as major challenges for a sub-set of patients. Civil society groups, NGOs and communities are substantially engaged in providing different services to DR-TB patients, especially in Ukraine, Romania and Tajikistan. Data from clinical records of 212 patients revealed that independent risk factors for unfavourable treatment outcome (death, loss to follow-up, failure) were culture-positivity at two months of treatment, history of treatment with second-line drugs and homelessness. More powerful, less toxic and shorter oral treatment regimens as well as comprehensive patient support are needed to improve treatment outcome of patients with DR-TB. 


\section{Introduction}

Drug-resistant tuberculosis (DR-TB) is a major challenge globally and in most of the countries in Eastern Europe and Central Asia (EECA). Nine of the world's 30 high DR-TB burden countries are located in the EECA region [1]. The estimated incidence of TB in the WHO European Region was 28 per 100,000 in 2018 [2] ranging from 2.7 per 100,000 in Iceland to 116 per 100,000 in Kyrgyzstan [3]. The prevalence of DR-TB between new and retreatment cases was $18 \%$ and $54 \%$, respectively, whereas the global averages were $3.4 \%$ and $18 \%$ respectively [2]. A substantial proportion of patients with DR-TB harbour extensively drug-resistant TB (XDR-TB) strains of Mycobacterium tuberculosis. Globally, the proportion of DR-TB put on treatment that had XDR-TB was $7.3 \%$ (11'403/156'071) in 2018; it was $14.8 \%$ (7351/49'696) in the European Region [2], and 18.2\% (1444/7926) in Ukraine [4]. Possible contributing factors for the high burden of DR-TB in EECA include weak health systems (especially after the collapse of the Soviet Union) [5,6], poorly conceptualised TB programmes [7], lack of attention/lack of resources, hospitalization, and migration [8]. Importantly, the domestic funding scheme for TB programmes in place in the majority of countries favours hospital admission with increased costs and risk of $M$. tuberculosis transmission [9-12].

The treatment outcomes of patients with DR-TB has been suboptimal: a total of 45,955 patients with multi-drug and rifampicin resistant TB (MDR/RR-TB) were started on second-line treatment in the EECA region in 2015; only 57\% were treated successfully (cured plus treatment completed). Among the 5482 XDR-TB cases, only $35 \%$ were treated successfully. The corresponding global figures were $55 \%$ and $34 \%$, respectively [1]. Recent evidence shows better results when bedaquiline is included in the regimen and its use is safe [13-15]. Globally research has investigated the reasons behind the sub-optimal outcomes among DR-TB patients [16], such as diagnostic delay leading to advanced disease, severe drug-resistance patterns, drug side effects, socio-economic and psycho-social conditions hindering good treatment adherence [17], and migration [18]. However, not much is known on the determinants of treatment outcomes in the EECA region.

The aim of this study was to determine the factors contributing to treatment outcomes observed among DR-TB patients in EECA taking advantage of the support received from the Global Fund for TB. The impact of provision of a continuum of care for risk groups and community engagement were also assessed.

\section{Materials and Methods}

Five countries were selected for this study (Azerbaijan, Belarus, Romania, Tajikistan and Ukraine) using a convenience sampling method. Study teams were composed of one national expert and one international expert (in Ukraine, there were two international experts). To ensure consistency, the same international researcher participated in all five country visits. A total of 21 regions (called oblasts) were visited in the selected countries. In each country, half of the selected regions had the highest and the other half the lowest treatment success rates (based on the 2013 cohort). In Azerbaijan and Ukraine, this selection criterion could not be fully met due to security concerns and due to the small number of DR-TB patients registered in some regions respectively.

In all five countries, the same quantitative and qualitative methodologies were used for data collection and analysis.

\section{Quantitative approaches}

A) A desk review of documents related to the DR-TB responses. Most documents included in the desk review were reports of National TB Programme (NTP) reviews and the Green Light Committee (GLC) missions for the period between 2010 and 2016, provided by the Global Fund and the respective National TB Programmes. The GLC is a regional mechanism supporting implementation of quality DR-TB responses by countries. The document review specifically looked at patient population groups, main challenges and recommendations related to treatment outcome.

B) An analysis of clinical records of DR-TB patients in selected health facilities of the five countries. In each selected region, one peripheral health facility was selected for the review of the patient charts. The review of the patient charts was performed to identify the characteristics of patients with DR-TB and to create an Excel-based database for establishing potential determinants of treatment outcome. Data extracted include patientrelated items (e.g., age, sex, body mass index - BMI), diagnostic results, disease-related items (e.g., disease location, comorbidities), treatment related items (e.g., number of previous TB treatment episodes, mode of directly observed therapy DOT), treatment regimens provided and treatment outcome. Charts of patients with DR-TB registered in 2013 were selected by asking in each visited health facility the healthcare providers to randomly select patient charts and present them to the study team. Descriptive analysis was done using frequency distributions. Bi-variate analysis and a multivariate logistic regression analysis were done to determine risk factors for unfavourable treatment outcomes; in a multivariate model, alcohol consumption, sex, HIV status and four of the five risk factors found to be statistically significant in the bi-variate analysis were included. The excluded risk factor was BMI: it could not be included because of the many missing values.

\section{Qualitative approaches}

Qualitative methods included:

A) In-depth interviews (IDIs) with providers. The IDIs were conducted with key informants at national and oblast level, with providers at health facility level and with NGO workers. A total of 156 in-depth interviews were completed among care providers (including NGO workers), programme staff and other stakeholders.

B) Interviews as well as Focus Group Discussions (FGDs) with DR-TB patients to explore their views about DR-TB and its treatment. Patient interviews and FGDs were performed at peripheral health facilities with DR-TB patients using semistructured interview/FDG guides. A total of 8 FGDs (4 in Ukraine, 2 in Belarus, 1 in Romania and 1 in Tajikistan) and 20 patient interviews (4 in Ukraine, 1 in Belarus, 7 in Romania, 3 in Tajikistan and 5 in Azerbaijan) were conducted with DR-TB patients (4 of them were co-infected with HIV). Most of these DR-TB patients were still on treatment at the time of the FGD or interview, respectively. None of the patients with unfavourable outcome were interviewed.

A focus during the patient and provider interviews/FGDs was factors hindering and factors promoting successful completion of treatment. During IDIs and FGD, notes were taken to capture the participants' statements. The interviews and FGDs were conducted in the local languages, using a question guide. The notes were translated into English. We used the framework approach for qualitative analysis [19]. 
The findings from the qualitative and quantitative methods were triangulated when appropriate [20]. All interviewees (including participants of FGDs) gave oral consent to be interviewed. Ethical clearance was obtained from relevant authorities of each country.

\section{Results}

\section{Desk reviews}

Thirty-eight reports were reviewed (13 from Belarus, 11 from Ukraine, 6 from Romania, 4 from Tajikistan and 4 from Azerbaijan). Sixteen of the 38 reports were GLC mission reports. Patient population groups identified included: prisoners and people living with $\mathrm{HIV}$, mentioned in a majority of the reports (in 29 and 27 reports, respectively); homeless people, illicit drug users and migrants, mentioned in one third of the reports reviewed (in 13, 13 and 12 reports, respectively); people struggling with alcohol addiction, mentioned in only four reports (in 3 reports from Belarus and 1 report from Ukraine); refugees/internally displaced people, mentioned in three reports; and people with mental disorders, mentioned in two reports.

The main challenges mentioned in the reports were of financial and/or management nature or related to adverse events of the medicines, as summarised in Table 1.

The most common recommendations found in the reports that were related to treatment outcomes referred to general programme management, regimen composition, clinical management and social support for the patients (Table 2).

\section{TB services in the five countries: findings from the interviews with providers}

In all five countries the national TB programmes still have a vertical structure, being implemented separately from other healthcare programmes. Although some integration into the primary health care system (PHC) already exists, further involvement of PHC facilities is feasible and recommended.

In all five countries, the majority of TB and DR-TB patients are hospitalized at least during the initial phase of treatment and until smear- and/or culture conversion. The number of "TB hospital beds" has recently been reduced to liberate financial resources for other aspects of TB care. However, financing per TB hospital bed occupied still prevails. Ambulatory treatment is being promoted although the rate and degree of implementation varies by country.
Interviews with stakeholders in the five countries indicated that alcoholism and homelessness are major challenges for a subset of patients and that support for such patients needs to be strengthened. Civil society groups, NGOs and communities are substantially engaged in providing different services to DR-TB patients in Ukraine, Romania and Tajikistan; the NGO engagement is less strong in Azerbaijan and Belarus. Details on NGO involvement in the five countries are summarised below and in Table 3.

\section{Belarus}

Red Cross Belarus provides psychosocial support to TB/DRTB patients; it organizes the consultation with the organization's psychologist if needed, and offers social assistance (such as help with administrative procedures, e.g., getting documents). The Red Cross also helps with transportation, especially for patients who reside far from the treating sites and provides small monetary incentives to patients as a reward for treatment adherence. The focus of the NGO "Defeat TB together", is advocacy towards the Ministry of Health to defend the TB patients' interests.

\section{Ukraine}

There are a few NGOs providing services to TB/DR-TB patients. The two biggest organizations that are active throughout the country are the Red Cross of Ukraine and the All-Ukrainian Network of People living with HIV. The patient organization 'Ukraine against TB' ' has started active work in Kiev, participating in the development of TB control activities. "Ukraine against

Table 1. Identified challenges in the reports of the five countries. Category of challenges (identified in at least 3 reports) n

\begin{tabular}{lc} 
Financial and/or management challenge & 11 \\
Programme management & 10 \\
\hline Side effects of medicines & 6 \\
Management, other & 5 \\
\hline Social support for patient in general & 4 \\
Ancillary drugs (e.g., limited access) & 3 \\
\hline Other challenges & 6 \\
\hline
\end{tabular}

Table 2. Most common recommendations related to treatment completion.

\begin{tabular}{lc} 
Focus of recommendation & Number of recommendations with this focus \\
Programme management & 43 \\
Design/composition of regimen & 20 \\
\hline Clinical management & 14 \\
Social support for patient (in general) & 14 \\
\hline Financial and/or management issue & 11 \\
Side effects, ancillary drugs & 10 \\
\hline Training & 9 \\
Various other specific support for patients, e.g., food or psychological support & 5 \\
\hline Management other than typical programme issues & 5 \\
Community-based DOT/care & 4 \\
\hline DOT, directly obsed therpy &
\end{tabular}

DOT, directly observed therapy. 
TB" works closely with the NTP, with a focus on ambulatory treatment promotion. The Red Cross in Ukraine supports, through the Global Fund grant, DR-TB patients during treatment. The treatment adherence support includes enabling support (e.g., transportation tickets and cash payments that patients can use to cover some of their expenses), food/hygiene sets, and clothes. Furthermore, a few NGOs provide psychosocial consultation and social support (e.g., help with missing documents, or getting registration or application to state benefits).

\section{Romania}

The main role of NGOs in Romania is to support the TB-specific Multi-Disciplinary Teams (MDTs) approach, implemented in 6 regions. MDTs consist of a social worker, a psychologist and a doctor/pulmonologist. With funding received from foreign aid, the NGO “Association for Supporting MDR-TB patients" hires social workers and psychologists dedicated to TB patients. These specialists are based in the TB department of regional hospitals and collaborate with TB health providers on case evaluation and risk assessment. Social workers and psychologists from the MDTs provide face-to-face and phone-based support. They also provide food or transport vouchers, as well as administrative support such as establishment of missing documents and state benefit applications (which are often requests for medical pensions of TB patients). MDTs also refer patients to have DOT in dispensaries close to their place of residence. The NGO involvement in TB treatment and care has led to a form of integrated

Table 3. Overviews of the NGO activities in reference to TB care in the five countries.

\begin{tabular}{|c|c|c|c|c|c|}
\hline Criteria & Belarus & Ukraine & Romania & Tajikistan & Azerbaijan \\
\hline $\begin{array}{l}\text { Main } \\
\text { NGOs/CSOs active in DR-TB identified } \\
\text { during field visit }\end{array}$ & $\begin{array}{l}\text { Red Cross } \\
\text { Belarus } \\
\text { Republican public } \\
\text { association "Defeat } \\
\text { Tuberculosis } \\
\text { Together" }\end{array}$ & $\begin{array}{l}\text { Red Cross } \\
\text { of Ukraine } \\
\text { All-Ukrainian } \\
\text { Network of People } \\
\text { living with HIV } \\
\text { Patient organization } \\
\text { "Ukraine against TB" } \\
\text { Other local } \\
\text { CSOs }\end{array}$ & $\begin{array}{l}\text { Romanian Angel } \\
\text { Appeal Foundation } \\
\text { Centre for Health } \\
\text { Policies and Services } \\
\text { Association of TB } \\
\text { patients } \\
\text { The Association for } \\
\text { Supporting } \\
\text { MDR-TB Patients } \\
\text { ARAS (working with } \\
\text { IDUs) } \\
\text { Salvati Copiii (Save } \\
\text { the Children) } \\
\text { UNOPA } \\
\text { Romanian Red Cross }\end{array}$ & $\begin{array}{l}\text { Coalition "Stop TB } \\
\text { partnership, } \\
\text { Tajikistan", } \\
\text { Youth led-NGO } \\
\text { "Young generation } \\
\text { of Tajikistan" } \\
13 \text { organizations, } \\
\text { mostly in the field } \\
\text { of HIV/AIDS. } \\
\text { Two organisations } \\
\text { ("EFEW" and } \\
\text { "Red Tulip") are } \\
\text { active in the prison } \\
\text { sector }\end{array}$ & $\begin{array}{l}\text { TB Azerbaijan } \\
\text { Coalition, composed } \\
\text { of several NGOs: } \\
\text { "Saglamliga } \\
\text { Khidmat", "Hayat", } \\
\text { "Azerbaijan Red } \\
\text { Crescent Society", } \\
\text { "Unit of Professional } \\
\text { TB doctors and } \\
\text { Pulmonologists" } \\
\text { and "Veremsiz } \\
\text { Dunya" NGO }\end{array}$ \\
\hline Levels of intervention of NGOs/CSOs & $\begin{array}{l}\text { Red Cross } \\
\text { Belarus has national } \\
\text { coverage } \\
\text { Mostly local } \\
\text { work by CSOs }\end{array}$ & $\begin{array}{l}\text { Some have national } \\
\text { coverage } \\
\text { Local CSOs work at } \\
\text { oblast level or below }\end{array}$ & $\begin{array}{l}\text { Some work done } \\
\text { centrally } \\
\text { Coverage of several } \\
\text { regions } \\
\text { Overall very active } \\
\text { NGO work }\end{array}$ & $\begin{array}{l}\text { No national coverage, } \\
\text { Mostly local work by } \\
\text { CSOs }\end{array}$ & $\begin{array}{l}\text { Mostly local work by } \\
\text { CSOs }\end{array}$ \\
\hline Type of support & $\begin{array}{l}\text { Working with } \\
\text { children with TB } \\
\text { Psychological } \\
\text { rehabilitation } \\
\text { Social support } \\
\text { packages }\end{array}$ & $\begin{array}{l}\text { Participation in the } \\
\text { development of TB } \\
\text { control activities } \\
\text { Promotion of } \\
\text { ambulatory treatment } \\
\text { Provision of } \\
\text { psychological or } \\
\text { social support to } \\
\text { TB patients }\end{array}$ & $\begin{array}{l}\text { Political advocacy } \\
\text { TB and DR-TB care } \\
\text { in an integrated } \\
\text { response with the } \\
\text { national TB } \\
\text { programme } \\
\text { Community-based } \\
\text { support through } \\
\text { peer supporters, } \\
\text { social workers } \\
\text { and psychologists, } \\
\text { Multi-disciplinary } \\
\text { teams. }\end{array}$ & $\begin{array}{l}\text { TB and DR-TB care } \\
\text { including screening } \\
\text { contacts, TB } \\
\text { infection control and } \\
\text { treatment monitoring } \\
\text { Psychosocial support } \\
\text { to TB patients } \\
\text { Incentive payment } \\
\text { to patients } \\
\text { Support with } \\
\text { transportation } \\
\text { Administrative } \\
\text { support } \\
\text { Research }\end{array}$ & $\begin{array}{l}\text { Food support and } \\
\text { psychosocial } \\
\text { support } \\
\text { Advocacy with public } \\
\text { authorities } \\
\text { Public awareness } \\
\text { raising on TB }\end{array}$ \\
\hline Provision of DOT & No & $\begin{array}{l}\text { Yes, home-based } \\
\text { DOT through hired } \\
\text { nurses }\end{array}$ & $\begin{array}{l}\text { Home-based for } \\
\text { children, otherwise } \\
\text { in ambulatory }\end{array}$ & $\begin{array}{l}\text { Yes, different } \\
\text { models: } \\
\text { (a) home-based } \\
\text { DOT through trained } \\
\text { volunteers, } \\
\text { (b) health } \\
\text { facility-based DOT } \\
\text { through trained } \\
\text { health workers }\end{array}$ & $\begin{array}{l}\text { Not confirmed by data } \\
\text { collection evidence }\end{array}$ \\
\hline
\end{tabular}


support services for TB patients, which is widely appreciated, by patients and providers. However, to a certain extent, NGO-led TB services developed parallel systems to public institutions: the NGOsupported social workers do not belong to the Ministry of Labour and Social Affair and have no institutional linkage to the cadre of public social workers accountable to city halls. Collaboration between the two cadres of social workers takes place but does not seem systematic and largely depends on personal initiatives.

\section{Tajikistan}

There are several NGOs involved in TB, TB/HIV and DR-TB care, ranging from screening contacts, $\mathrm{TB}$ infection control to monitoring of treatment. Some of them provide psychosocial support to TB patients, provide payments to patients as an incentive to stay in treatment, help with transportation, and help with getting documents and other necessary paperwork. However, this work is not yet countrywide. Financing for their operations is to a large extent provided through the Global Fund. Some local administrations contribute to a small extent.

\section{Azerbaijan}

There are several NGOs involved in health care, but just two are active in TB care. The first is an NGO called "Association of professional unit of TB specialists and Pulmonologists" (APP). They offer support to the TB patients (mainly food support and psychosocial support). In order to solve the problem of TB treatment after discharge from prisons, a grant was sought from the Global Fund and in March 2011, an NGO called 'Saglamliga Khidmat' (translated as Support to Health) launched a project for ex-prisoner TB patients. This initiative led to a drastic reduction of lost to follow-up after release to almost zero and the treatment success rate for new sputum smear-positive drug-susceptible TB patients increased to $88 \%$.

\section{Findings from the interactions with patients and providers related to treatment outcome}

\section{Factors perceived to promote successful treatment outcome}

In FGDs and patient interviews, the commonly mentioned factors motivating the patients were the desire to survive, a good

Table 3. Continued from previous page.

\begin{tabular}{|c|c|c|c|c|c|}
\hline Criteria & Belarus & Ukraine & Romania & Tajikistan & Azerbaijan \\
\hline Target population/beneficiaries & $\begin{array}{l}\text { DR-TB/TB patients } \\
\text { including children }\end{array}$ & $\begin{array}{l}\text { DR/TB/HIV patients } \\
\text { DR/TB patients } \\
\text { without HIV }\end{array}$ & $\begin{array}{l}\text { DR/TB patients } \\
\text { IDU, DR/TB patients } \\
\text { with HIV }\end{array}$ & $\begin{array}{l}\text { TB patients } \\
\text { DR-TB patients } \\
\text { TB/HIV patients }\end{array}$ & $\begin{array}{l}\text { DR/TB patients } \\
\text { DR-TB-affected } \\
\text { former prisoners }\end{array}$ \\
\hline $\begin{array}{l}\text { Participation in national coordination } \\
\text { body on TB }\end{array}$ & $\begin{array}{l}\text { No evidence found } \\
\text { during country visit }\end{array}$ & $\begin{array}{l}\text { Yes, } \\
\text { NGO participation in } \\
\text { national coordination } \\
\text { body, including } \\
\text { representatives of } \\
\text { key population } \\
\text { (e.g., MSM) }\end{array}$ & $\begin{array}{l}\text { All main NGOs } \\
\text { represented in the } \\
\text { National Country } \\
\text { Coordination } \\
\text { mechanism }\end{array}$ & $\begin{array}{l}\text { Yes, } \\
\text { NGO representation } \\
\text { in the National } \\
\text { Coordination } \\
\text { Committee on TB, } \\
\text { AIDS and Malaria }\end{array}$ & $\begin{array}{l}\text { NGO Saglamliga } \\
\text { Khidmat", civil society } \\
\text { partner for the TB } \\
\text { Europe Coalition, is a } \\
\text { member of the CCM }\end{array}$ \\
\hline $\begin{array}{l}\text { Recipient of GF grant } \\
\text { (directly or indirectly) }\end{array}$ & Yes, indirectly & Yes & $\begin{array}{l}\text { Romanian Angel } \\
\text { Appeal is principal } \\
\text { recipient; many other } \\
\text { NGOs receive funding } \\
\text { from GF grant }\end{array}$ & $\begin{array}{l}\text { Yes, and of funds } \\
\text { from other donors }\end{array}$ & Yes \\
\hline Overall assessment & $\begin{array}{l}\text { A small number of } \\
\text { NGOs and CSOs } \\
\text { provide limited social } \\
\text { and psychological } \\
\text { support } \\
\text { NGO involvement } \\
\text { remains rather } \\
\text { marginal in a } \\
\text { centrally-controlled, } \\
\text { national TB response }\end{array}$ & $\begin{array}{l}\text { NGOs are well } \\
\text { represented and } \\
\text { engaged in the TB } \\
\text { response in Ukraine, } \\
\text { and provide } \\
\text { complementary } \\
\text { services to the NTP } \\
\text { in close cooperation } \\
\text { with health } \\
\text { providers }\end{array}$ & $\begin{array}{l}\text { NGOs are a major } \\
\text { driving force in the } \\
\text { national DR/TB } \\
\text { response in filling } \\
\text { many gaps of the } \\
\text { public response } \\
\text { They have fostered } \\
\text { the development of } \\
\text { an advanced model } \\
\text { of integrated care for } \\
\text { DR/TB patients } \\
\text { The numerous NGO } \\
\text { actors and } \\
\text { NGO-funded } \\
\text { services can lead to } \\
\text { parallel systems and } \\
\text { multiple layers of } \\
\text { interventions } \\
\text { Of all case studies, it is } \\
\text { the most effective } \\
\text { involvement of NGOs } \\
\text { in the TB response }\end{array}$ & $\begin{array}{l}\text { NGOs are well } \\
\text { represented, active } \\
\text { and frequent fund } \\
\text { recipients or } \\
\text { implementing } \\
\text { partners of foreign } \\
\text { aid donors in the } \\
\text { field of TB or HIV. } \\
\text { The integration of } \\
\text { NGO TB work within } \\
\text { the national } \\
\text { response } \\
\text { remains rather } \\
\text { limited }\end{array}$ & $\begin{array}{l}\text { A small number of } \\
\text { NGOs provide limited } \\
\text { social and } \\
\text { psychological } \\
\text { support but they } \\
\text { have formed a } \\
\text { coalition which is a } \\
\text { positive development } \\
\text { towards greater } \\
\text { coordinated } \\
\text { action from civil } \\
\text { society in the } \\
\text { field of TB } \\
\text { Contacts are } \\
\text { established with the } \\
\text { national response } \\
\text { system but no } \\
\text { systematic or } \\
\text { integrated } \\
\text { collaboration was } \\
\text { visible }\end{array}$ \\
\hline
\end{tabular}

ARAS, Romanian Association Against AIDS; CCM, Country Coordinating Mechanism; CSO, Civil society organisation; DR, drug resistant; NGO, non-governmental organisation; DOT, directly observed therapy; GF, Global Fund; IDU, Injecting drug user; MSM, men who have sex with men; UNOPA, National Union of Organizations of People Affected by HIV/AIDS. 
patient-provider relationship, family support and food as incentive. Table 4 presents these findings.

The patients were specifically asked if receiving psychological support through a psychologist would be helpful. In four of the eight FGDs (in Ukraine and Belarus), this was seen as helpful. Roughly half of the interviewed patients $(9 / 20)$ saw this as helpful. In Romania, support seemed strongest (5 of 7 saw it as helpful). Similarly, the patients were asked if guided patient group discussions would be helpful. In all except one FGD and in seven of the twenty patient interviews was this seen as helpful or possibly helpful. A patient from Romania explained that she would like to provide advice to patients (as a volunteer), listen to them and share her own experience. She added that willingness and awareness of patients is crucial.

Among the positive comments of patients regarding group discussions were:

- "Yes, mutual peer support is very important through personal relationships" (Ukraine).

- "Moral support from other patients means a lot and would be helpful" (Ukraine).

Many of the just mentioned factors were also mentioned by the various types of providers. Home-based DOT (treatment at home of patient) was mentioned as a facilitating factor for treatment by the providers in all five visited countries. Mostly, patients mentioned this only indirectly. Linked to this is video-observed treatment (VOT); at the time of the field work of the study, Belarus had already had positive experience with VOT. And as of October 2019, more than 1000 patients had experienced VOT (Skrahina 2019 , personal communication). In Ukraine, a desire for VOT was expressed.

In general, across the five countries, providers indicated that they understood the difficult situations patients face and believe that provision of comprehensive patient support is critical. However, a few participants tended to blame patients due to lack of understanding of the behaviour of some patients including those who are marginalized and those with mental health issues and who may require a high degree of professionalism and positive attitude from healthcare providers.
Approaches that promote successful treatment outcome mentioned by the respondents include good management of side effects, provision of more information about the medicines' side effects to the patients, shorter treatment regimens, good patientprovider relationship, food as incentives, home-based DOT, family and psychological support, guided patient group discussion and video-observed therapy.

\section{Factors perceived to discourage patients from completing treatment}

Factors mentioned in FGDs and patient interviews that discourage patients from completing treatment are summarized in Table 5.

Similar factors were also mentioned by the various types of providers. The following were obstacles mentioned by the providers in at least 4 of the countries visited but not commonly mentioned by the patients:

- Patients' lack of comprehensive information about TB and its treatment at the start of treatment

- Stigma attached to TB

- Patients' economic needs and employment seen as incompatible with treatment

Suggestions were made on how to facilitate successful treatment outcome: giving monthly a small amount of money to the patient and at the end of treatment a larger amount. Similarly, the DOT provider can also receive a financial incentive. It was also stated that more ambulatory treatment would help though some providers expressed doubt if all patients would be able to manage ambulatory treatment.

\section{Review of charts of patients with DR-TB}

\section{Description of the patients, including co-morbidities}

Charts of 212 patients (77 in Romania, 65 in Ukraine, 30 in Azerbaijan, 23 in Tajikistan and 17 in Belarus) registered in 2013 in the selected health facilities were reviewed and data were

Table 4. Factors perceived or mentioned by patients to promote successful treatment outcome.

Factor $\begin{gathered}\text { Mentioned } \\ \text { in FGDs* }\end{gathered} \quad$ in patientioned interviews ${ }^{\circ} \quad$ Examples

The desire to survive/The knowledge that cure is attainable $\quad$ BLR, TJK, UKR $\quad$ AZE, ROM, TJK, UKR

We understand that we need to go for treatment until the end (TJK)

\begin{tabular}{|c|c|c|c|}
\hline Good patient-provider relationship & BLR, ROM, TJK & AZE, ROM & $\begin{array}{l}\text { The relationship with the nurses and doctors } \\
\text { is good (AZE) }\end{array}$ \\
\hline Family support & BLR, ROM & AZE, ROM, TJK & $\begin{array}{l}\text { My father gave great support, without him } \\
\text { I would not have survived (TJK) }\end{array}$ \\
\hline Food as incentive & BLR & AZE, TJK & $\begin{array}{l}\text { Patient needs to eat good food - it is also } \\
\text { like medicine (AZE) }\end{array}$ \\
\hline Concern / love about family, children & UKR & ROM & $\begin{array}{l}\text { My concern about my family and children } \\
\text { (ROM) }\end{array}$ \\
\hline Moral support from co-patients & BLR & ROM & $\begin{array}{l}\text { We as patients morally support each other } \\
\text { (BLR) }\end{array}$ \\
\hline $\begin{array}{l}\text { Good management of side effects/more information on side } \\
\text { effects/less side effects }\end{array}$ & BLR, ROM, UKR & AZE & $\begin{array}{l}\text { There are many side effects; we would like } \\
\text { to have treatment with "good" drugs (BLR) }\end{array}$ \\
\hline The hope to go back to work soon & UKR, BLR & - & $\begin{array}{l}\text { What motivates is the hope that after the } \\
\text { treatment is finished I will find a job (UKR) }\end{array}$ \\
\hline
\end{tabular}

*No FGD was done in Azerbaijan; ' in Belarus, only one patient interview was done (with a HIV-positive patient): this conversation did not yield any meaningful information; BLR, Belarus; TJK, Tajikistan; UKR, Ukraine; ROM, Romania; AZE, Azerbaijan. Mentioned in only one country were: i) shorter and more supportive treatment (UKR); ii) ambulatory treatment (UKR); iii) financial incentives (ROM); iv) health staff giving explanations and hope (BLR); v) social support (AZE); vi) religion (UKR); (vii) support from friends (ROM); and viii) being well informed by health staff (ROM). 
extracted. Most of the 212 patients were male (71\%). The median age was 41 years (range: 11 to 79 years). Seventy five percent of the patients were unemployed when their TB illness began. The median bodyweight at baseline was $62 \mathrm{~kg} ; 17 \%$ (37/212) had a bodyweight below $50 \mathrm{~kg}$. Among the 105 patients with information on height and weight, $18 \%(\mathrm{n}=19)$ had low BMI $\left(<18.5 \mathrm{~kg} / \mathrm{m}^{2}\right)$. Three patients had extra-pulmonary TB and 209 had pulmonary TB. Sixty-nine percent of the patients (147/212) had at least one cavity in their chest radiography and $36 \%(n=76)$ had bilateral disease and at least one cavity. Of the 212 DR-TB patients, 201 (95\%) had records of HIV status; 9.4\% (20/212) were HIV-positive. The proportion of HIV-positive DR-TB cases was high in Ukraine: $24.6 \%$ (16 of 65 ). It was low in Belarus ( 1 of 17), Romania ( 2 of 77 ) and Azerbaijan (1 of 30). None of the 23 patients of Tajikistan was HIV-positive. Eight percent (16) had diabetes mellitus.

\section{Patient features at the initiation of treatment}

At initiation of treatment, 45\% (96) had a record of smoking cigarettes, 30\% (64) of regularly consuming alcohol, and 5\% (11) of using illicit drugs. Eleven percent (23) had a history of detention and 7\% (15) homelessness as shown in Table 6.

Sixty-five percent (137) had a history of at least one previous TB treatment; among them, $24.1 \%(33 / 137)$ had a treatment outcome of "lost to follow-up". Among the 212 patients, $14.6 \%$ had had three or more previous TB treatment episodes and $19.8 \%$ had a history of at least one previous treatment for DR-TB. At baseline, $66.5 \%$ (141) had positive smears, $86 \%$ (183) positive culture and $57 \%(120)$ positive smear and culture results. Xpert MTB/RIF testing was done for 49 patients in three of the countries (none of the patients in Azerbaijan and Tajikistan had Xpert testing in 2013) and of these, 45 had RR.

Table 5. Factors perceived or mentioned by patients to discourage them from completing treatment.

\begin{tabular}{|c|c|c|c|}
\hline Factor & $\begin{array}{l}\text { Mentioned } \\
\text { in FGDs* }\end{array}$ & $\begin{array}{c}\text { Mentioned } \\
\text { in patient interviews }\end{array}$ & Examples \\
\hline Side effects & BLR, TJK, UKR & AZE, ROM, TJK, UKR & $\begin{array}{l}\text { I had suffered hearing loss, but it is better to } \\
\text { be deaf then dead (ROM) }\end{array}$ \\
\hline The long duration of treatment & BLR, UKR & AZE, ROM, TJK & $\begin{array}{l}\text { Hearing that treatment would last for two } \\
\text { years was shocking (ROM) } \\
\text { Please invent something so that the } \\
\text { treatment is not so long! (UKR) } \\
\text { I cannot afford to stay out of work, meaning } \\
\text { I have no time for treatment }\end{array}$ \\
\hline Lack of general support or family support & TJK & ROM, TJK & Nobody cares if you die or live (TJK) \\
\hline Getting fed up with the daily routine & TJK & AZE, UKR & $\begin{array}{l}\text { I feel very tired doing the same thing every } \\
\text { day (UKR) }\end{array}$ \\
\hline No trust in treatment or healthcare providers & - & AZE, TJK & $\begin{array}{l}\text { Some do not trust the doctors and think they } \\
\text { will not get cured (TJK) }\end{array}$ \\
\hline Hospital conditions not good & UKR & ROM & $\begin{array}{l}\text { It would be nice if the hospital facilitated } \\
\text { light sport activities such as table tennis or } \\
\text { fitness exercises (UKR) }\end{array}$ \\
\hline Anxiety, having bad thoughts, shock and disbelief & UKR & AZE & I had many bad thoughts (AZE) \\
\hline
\end{tabular}

Table 6. Reported behavioural and social characteristics of the 212 patients.

\begin{tabular}{|c|c|c|c|}
\hline Behavioural and social feature & Categories & Number & Percentage \\
\hline Smoking at baseline & $\begin{array}{c}\text { Yes } \\
\text { No } \\
\text { Unclear/not recorded }\end{array}$ & $\begin{array}{l}96 \\
80 \\
36\end{array}$ & $\begin{array}{l}45.3 \\
37.7 \\
17.0\end{array}$ \\
\hline Alcohol consumption at baseline & $\begin{array}{c}\text { Yes } \\
\text { No } \\
\text { Unclear/not recorded }\end{array}$ & $\begin{array}{c}64 \\
128 \\
20\end{array}$ & $\begin{array}{c}30.2 \\
60.4 \\
9.4 \\
\end{array}$ \\
\hline Illicit drug use at baseline & $\begin{array}{c}\text { Yes } \\
\text { No } \\
\text { Unclear/not recorded }\end{array}$ & $\begin{array}{c}11 \\
178 \\
23\end{array}$ & $\begin{array}{c}5.2 \\
84.0 \\
10.8\end{array}$ \\
\hline History of detention (imprisonment) & $\begin{array}{c}\text { Yes } \\
\text { No } \\
\text { Unclear/not recorded }\end{array}$ & $\begin{array}{c}23 \\
187 \\
2\end{array}$ & $\begin{array}{c}10.8 \\
88.2 \\
0.9\end{array}$ \\
\hline Homeless in the past or at baseline & $\begin{array}{c}\text { Yes } \\
\text { No } \\
\text { Unclear/not recorded }\end{array}$ & $\begin{array}{c}15 \\
157 \\
40\end{array}$ & $\begin{array}{c}7.1 \\
74.1 \\
18.9 \\
\end{array}$ \\
\hline
\end{tabular}


The most common drug resistance patterns at baseline were resistance to rifampicin and isoniazid $(\mathrm{RH})(16 \% ; \mathrm{n}=34)$ and resistance to RH plus some other first-line drugs $(47 \%$; $=100)$. Forty-six patients $(21.7 \%$ ) had pre-XDR (21 had MDR-TB with resistance to a fluoroquinolone and 25 had resistance to an injectable) and 19 (9\%) patients had XDR-TB (Table 7).

\section{Mode of treatment}

Most patients (81\%) were hospitalised. Among the 172 patients who were hospitalised, 19\% (33) were in hospitals for up to two months only, $71 \%$ (122) were hospitalised for between 2 to 12 months and $8 \%$ (14) for more than 12 months.

For most patients $(78.5 \%$ of the 195 for whom this was applicable), the place of DOT during ambulatory treatment was at a health facility; for $10.3 \%$ it was at their residence. Fourteen patients $(7.2 \%)$ had DOT in other places or had more than one mode of DOT.

\section{Treatment outcome}

After two months of treatment, 22.3\% (45/202) were still smear-positive and 38.2\% (73/191) still culture-positive.

During the time of the patient chart review, 21 patients were still on treatment and excluded from the cohort analysis for treatment outcome. Among the remaining 191 patients, 58.6\% (112) had favourable treatment outcome (cure or completed treatment) and $75(39.3 \%)$ had unfavourable treatment outcome: $12.6 \%(24)$ died, $7.3 \%$ (14) were lost to follow-up, and 19.4\% (37) failed treatment. Furthermore, 2.1\% (4) had unclear treatment outcome (two of them were transferred to prison).

In Romania, some of the extracted data were from patients under a Global Fund grant and others were under the NTP without Global Fund support. While $75 \%$ of the patients under the "Global Fund grant" (15 of 20) had favourable treatment outcome, only $26.3 \%(15 / 57)$ of the patients under NTP (not supported by Global Fund) had favourable treatment outcome $(\mathrm{p}=0.0001)$.

In Azerbaijan, all 30 patients whose patient charts were reviewed were under Global Fund support; their treatment success rate was $76.7 \%$ (23/30). A similar disaggregation was not available for patients registered in the other three countries.

In bivariate analysis, nine potential risk factors for unfavourable treatment outcome (including HIV status) were included. BMI $<18.5 \mathrm{~kg} / \mathrm{m}^{2}$, bilateral lung disease with at least one cavity, culture-positivity at 2 months of treatment, previous history of receiving second-line drugs and homelessness in the past or at baseline were significant risk factors for unfavourable treatment outcome $(\mathrm{p}<0.005$ for all). Alcohol consumption at baseline was a marginally significant risk factor $(\mathrm{p}=0.08)$.
In a multivariate analysis, the independent risk factors for unfavourable treatment outcome were culture-positivity at two months of treatment, history of treatment with second-line drugs and homelessness.

Table 8 presents the findings of the bi- and multivariate analysis.

\section{Discussion}

The main challenges to complete treatment for DR-TB identified in our study include i) a long regimen with often significant side effects and emotional distress; ii) long hospitalization resulting in separation from family and friends and interruption or termination of breadwinning activities; iii) lack of support, be it general support or support from family; and iv) challenging life situations for a sub-set of patients such as alcoholism and homelessness. In the global TB community, the awareness is in general high for the need for additional medical support (and partly also social support) for some sub-groups, e.g., HIV-positive TB patients and TB patients with drug addiction. Other sub-groups however, such as patients suffering from alcoholism and homeless patients, receive less attention and do not feature prominently in the general discourse of the decision makers of TB care. A systematic review provided evidence that alcohol consumption during treatment is a predictor for unsuccessful outcome [21]. Alcoholism is a major health threat in many of the EECA countries [22]. Accordingly, alcohol treatment interventions should be integrated into routine TB care, as was done in Tomsk, Russia [23]. Other studies in the EECA have also identified these or similar challenges. For instance, a study in Armenia found that in addition to economic reasons, poor tolerance of and poor response to treatment were the main factors associated with loss to follow-up [24].

Interestingly, the potentially severe economic repercussions (e.g., loss of work) linked to the long treatment were barely mentioned as a challenge in the five countries. This could also be due to the fact that majority of the patients were unemployed during initiation of treatment.

Based on the qualitative and quantitative findings, the following programmatic changes should be implemented or strengthened to improve treatment outcome: i) use of shorter regimens; ii) avoiding unnecessary hospitalization and an emphasis on ambulatory, community-based treatment; and iii) comprehensive support (material and emotional support) for DR-TB patients on treatment, considering the whole family situation. A recent systematic review found that material and psychosocial support reduced the propor-

Table 7. Drug resistance at baseline (212 cases).

\begin{tabular}{lcc} 
Drug resistance patterns (at baseline) & Number & Percentage \\
Poly-drug resistance* & 3 & $1.4 \%$ \\
Resistance to rifampicin only & 5 & $2.4 \%$ \\
\hline Resistance to rifampicin and isoniazid (RH) & 34 & $16.0 \%$ \\
Resistance to RH plus at least one other first-line drug & 100 & $47.2 \%$ \\
\hline Resistance to RH plus at least one fluoroquinolone & 21 & $9.9 \%$ \\
Resistance to RH plus at least one injectable & 25 & $11.8 \%$ \\
\hline Extensively drug-resistant tuberculosis & 19 & $9.0 \%$ \\
Other drug resistance or not clear & 5 & $2.4 \%$ \\
\hline
\end{tabular}

*Resistance to more than one first-line drug other than both isoniazid and rifampicin; RH, rifampicin and isoniazid. 
Table 8. Determinants of unfavourable treatment outcome, bi- and multivariate analysis.

\begin{tabular}{|c|c|c|c|}
\hline Risk factor & $\begin{array}{l}\text { Odds ratio } \\
\text { (95\% confidence interval) }\end{array}$ & $\begin{array}{l}\text { Adjusted odds ratio } \\
\text { (95\% confidence interval) }\end{array}$ & p-value \\
\hline Culture-positive at 2 months & 3.1 (1.7 to 5.7$)$ & $2.6(1.2$ to 5.4$)$ & 0.01 \\
\hline Had previous SLD treatment & 3.8 (1.8 to 8$)$ & 3.0 (1.2 to 7.3$)$ & 0.015 \\
\hline Homeless in the past or at baseline* & 10.7 (2.3 to 49.1$)$ & $11.0(2.5$ to 78$)$ & 0.004 \\
\hline Bilateral disease with at least one cavity & $2.4(1.3$ to 4.5$)$ & $1.3(0.6$ to 2.8$)$ & 0.5 \\
\hline BMI below $18.5 \mathrm{~kg} / \mathrm{m}^{2}$ & 6.9 (2 to 23.8$)$ & Not included in the model ${ }^{\circ}$ & \\
\hline HIV-positive & $1.4(0.5$ to 3.5$)$ & $1.5(0.4$ to 5.0$)$ & 0.5 \\
\hline Alcohol consumption at baseline & $1.8(0.93$ to 3.4$)$ & $1.2(0.5$ to 2.9$)$ & 0.6 \\
\hline History of detention & $0.9(0.3$ to 2.4$)$ & Not retained in the model & \\
\hline Hospitalisation for $>120$ days & $1.02(0.6$ to 1.9$)$ & Not retained in the model & \\
\hline
\end{tabular}

tion of DR-TB patients with loss to follow-up [25]. Among the 25 studies included in this systematic review, six were were from the EECA region. Another recent systematic review indicated that decentralised care improves treatment outcome [26].

Regarding the use of short regimens, it is crucial to build up the evidence base about which short regimens are effective for various resistance patterns in Europe and beyond [27-29]. For instance, can DR-TB patients with resistance to fluoroquinolones be treated with a modified short regimen that replaces the injectable with bedaquiline? There is an urgent need to support countries in their efforts to making use of the new TB drugs; a recent review found that fewer than $20 \%$ of persons likely to benefit from either bedaquiline or delamanid have received them [30]. Fundamental to treatment is that quality assured TB drugs and ancillary medicines are always available; this is by no means a given; there have been reports of stock outs of TB drugs in more than a dozen countries [31].

Our findings from the review of the patient charts on determinants of treatment outcome suggest that patients with the following features need special attention: i) Culture-positive at 2 months; ii) previous second-line treatment; iii) homelessness in the past or at baseline. While the first two risk factors call for a stronger regimen based on drug-susceptibility profile at treatment start, the risk factor of homelessness calls for special social support and comprehensive care. Furthermore, our analysis indicates that having a BMI below $18.5 \mathrm{~kg} / \mathrm{m}^{2}$ is a risk factor for unfavourable treatment outcome, as also found in China [32]. This indicates the need for provision of nutritional support for patients with a low BMI.

The multivariate analysis revealed that being culture-positive at two months of treatment is a strong risk factor for unfavourable treatment outcome. Other studies have also described this, for instance in Latvia [33,34] and Ethiopia [35]. Though some studies have already looked at sputum culture conversion as a prognostic marker for end of-treatment outcome [28,36-39], further studies are warranted on markers for unfavourable treatment outcome and follow-up of patients on treatment. Strengthening regimens including using new and repurposed drugs and oral regimens would be critical to improve DR-TB treatment outcome. The very recent recommendations from WHO [40] on the use of all-oral shorter regimens for treatment of DR-TB and XDR-TB (including BPaL for $\mathrm{XDR}-\mathrm{TB}$ ) and the pipeline of new drugs and regimens [41] are promising and would contribute to better treatment outcome of patients with DR-TB including XDR-TB.

The main limitations of this study were non-random selection of health facilities and that the views of people with unfavourable DRTB outcome were not included due to logistics. However, we believe that this study provides important information for NTPs and other stakeholders in their effort to improve the responses to DR-TB.

In conclusion, more powerful, less toxic and shorter oral treatment regimens as well as comprehensive patient support including through digital technologies are needed to improve treatment outcome of patients with DR-TB.

\section{References}

1. TBFacts.org [Internet]. High burden countries. Accessed on: 5 March 2020. Available from: https://tbfacts.org/high-burden-tb

2. WHO. Global tuberculosis report 2019. Annex 3: Regional and global profiles. Geneva; World Health Organization; 2019.

3. WHO. Global tuberculosis report 2019. Annex 4: Country Profiles. Geneva; World Health Organization; 2019.

4. WHO. Tuberculosis country profiles (Ukraine). Accessed on: 9 March 2020. Available from: https:/extranet.who.int/sree/ Reports?op=Replet\&name $=\% 2 \mathrm{FWHO} H \mathrm{HQ}$ Reports $\% 2 \mathrm{FG} 2 \%$ 2FPROD\%2FEXT\%2FTBCountryProfile\&ISO2=UA\&LAN= EN\&outtype $=$ html.

5. Roberts B, Karanikolos M, Rechel B. Health trends. In: Trends in health systems in the former Soviet countries. Observatory Studies Series, No. 35. Rechel B, Richardson E, McKee M, editors. Copenhagen; European Observatory on Health Systems and Policies: 2014.

6. Merker M, Blin C, Muna S, et al. Evolutionary history and global spread of the Mycobacterium tuberculosis Beijing lineage. Nature Genetics 2015;47:242-9.

7. Yablonskii PK, Vizel AA, Galkin VB, Shulgina MV. Tuberculosis in Russia. Its history and its status today. Am J Respir Crit Care Med 2015;191:372-6.

8. Institute of Medicine (US) Forum on Drug Discovery, Development, and Translation; Russian Academy of Medical Science. Drug-resistant tuberculosis in the Russian Federation. Section 3 in: The new profile of drug-resistant tuberculosis in Russia: A global and local perspective: Summary of a Joint Workshop. Washington (DC): National Academies Press (US); 2011.

9. Migliori GB, Nardell E, Yedilbayev A, et al. Reducing tuberculosis transmission: a consensus document from the World 
Health Organization Regional Office for Europe. Eur Respir J 2019;53. doi: 10.1183/13993003.00391-2019

10. Migliori GB, D'Ambrosio L, Centis R, et al. Guiding principles to reduce tuberculosis transmission in the WHO European Region. Copenhagen; WHO Regional Office for Europe; 2018.

11. Davtyan K, Hayrapetyan A, Dara M, et al. Key role of tuberculosis services funding mechanisms in tuberculosis control and elimination. Eur Respir J 2015; 45:289-91.

12. Gillini L, Davtyan K, Davtyan H, et al. TB financing in East Europe promotes unnecessary hospital admissions: the case of Armenia. J Infect Dev Ctries 2013; 7:289-92

13. Borisov SE, Dheda K, Enwerem M, et al. Effectiveness and safety of bedaquiline-containing regimens in the treatment of MDR- and XDR-TB: a multicentre study. Eur Respir J 2017;49:1700387.

14. Akkerman O, Aleksa A, Alffenaar JW, et al. Surveillance of adverse events in the treatment of drug-resistant tuberculosis: A global feasibility study. Int J Infect Dis 2019;83:72-6.

15. Collaborative Group for the Meta-Analysis of Individual Patient Data in MDR-TB treatment-2017, Ahmad N, Ahujia $\mathrm{SD}$, et al. Treatment correlates of successful outcomes in pulmonary multidrug-resistant tuberculosis: an individual patient data meta-analysis. Lancet 2018;392:821-34.

16. Kibret KT, Moges Y, Memiah P, Biadgilign S. Treatment outcomes for multidrug-resistant tuberculosis under DOTS-Plus: a systematic review and meta-analysis of published studies. Infect Dis Poverty 2017;6:7.

17. Franke MF, Appleton SC, Bayona J et al. Risk factors and mortality associated with default from multidrug-resistant tuberculosis treatment. Clin Infect Dis 2008;46:1844-51.

18. Liu CH, Li L, Chen Z, et al. Characteristics and treatment outcomes of patients with MDR and XDR tuberculosis in a TB referral hospital in Beijing: A 13-year experience. PLoS One 2011;6:e19399.

19. Smith J, Firth J. Qualitative data analysis: application of the framework approach. Nurse Res 2011;18:52-62.

20. Jick TD. Mixing qualitative and quantitative methods: Triangulation in action. Admin Sci Quart 1979;24:602-11.

21. Rehm J, Samokhvalov AV, Neuman MG, et al. The association between alcohol use, alcohol use disorders and tuberculosis (TB). A systematic review. BMC Public Health 2009;9:450.

22. WHO. Global status report on alcohol and health 2018. Geneva: World Health Organization; 2018.

23. Shin S, Livchits V, Connery HS, et al. Effectiveness of alcohol treatment interventions integrated into routine tuberculosis care in Tomsk, Russia. Addiction 2013;108:1387-96.

24. Sanchez-Padilla E, Marquer C, Kalon S, et al. Reasons for defaulting from drug-resistant tuberculosis treatment in Armenia: a quantitative and qualitative study. Int $\mathrm{J}$ Tuberc Lung Dis 2014;18:160-7.

25. Law S, Daftary A, O'Donnell $\mathrm{M}$, et al. Interventions to improve retention-in-care and treatment adherence among patients with drug-resistant tuberculosis: a systematic review. Eur Respir J 2019;53:1801030.

26. Ho J, Byrne AL, Linh NN, et al. Decentralized care for multidrug-resistant tuberculosis: a systematic review and metaanalysis. Bull World Health Organ 2017;95:584-93.
27. Lange C, Duarte R, Frechet-Jachym M, et al. Limited benefit of the new shorter multidrug-resistant tuberculosis regimen in Europe. Am J Respir Crit Care Med 2016;194:1029-31.

28. Sotgiu G, Tiberi S, D'Ambrosio L, et al. Faster for less: the new "shorter" regimen for multidrug-resistant tuberculosis. Eur Respir J 2016;48:1503-7.

29. Seung KJ, Hewison C. Now is the time for shorter all-oral regimens for multidrug-resistant tuberculosis. Lancet Glob Health 2019; 7:e706.

30. Cox V, Brigden G, Crespo RH, et al. Global programmatic use of bedaquiline and delamanid for the treatment of multidrugresistant tuberculosis. Int J Tuberc Lung Dis 2018 22:407-12.

31. Médecins Sans Frontières[Internet]. MSF calls on Global Fund Board to make urgent changes to prevent drug stock-outs and quality issues. Press release of 13 November 2018. Accessed on: 28 September 2019. Available from: https://msfaccess.org/ hundreds-thousands-peoples-treatment-risk-countries-transition-global-fund-support

32. Tang S, Tan S, Yao L, et al. Risk factors for poor treatment outcomes in patients with MDR-TB and XDR-TB in China: retrospective multi-center investigation. PLoS One 2013;5:e82943.

33. Holtz TH, Sternberg M, Kammerer S, et al. Time to sputum culture conversion in multidrug-resistant tuberculosis: predictors and relationship to treatment outcome. Ann Intern Med 2006;144:650-9.

34. Leimane V, Dravniece G, Riekstina V, et al. Treatment outcome of multidrug/extensively drug-resistant tuberculosis in Latvia, 2000-2004. Eur Respir J 2010;36:584-93.

35. Alene KA, Viney K, Yi H, et al. Comparison of the validity of smear and culture conversion as a prognostic marker of treatment outcome in patients with multidrug-resistant tuberculosis. PLoS One 2018;13:e0197880.

36. Kurbatova EV, Cegielski JP, Lienhardt C, et al. Sputum culture conversion as a prognostic marker for end-of-treatment outcome in patients with multidrug-resistant tuberculosis: a secondary analysis of data from two observational cohort studies. Lancet Respir Med 2015;3:201-9.

37. Javaid A, Ahmad N, Afridi AK, et al. Validity of time to sputum culture conversion to predict cure in patients with multidrug-resistant tuberculosis: A retrospective single-center study. Am J Trop Med Hyg 2018;98:1629-36.

38. Kurbatova EV, Taylor A, Gammino VM, et al. Predictors of poor outcomes among patients treated for multidrug-resistant tuberculosis at DOTS-plus projects. Tuberculosis (Edinb) 2012;92:397-403.

39. Bastard M, Sanchez-Padilla E, Hayrapetyan A, et al. What is the best culture conversion prognostic marker for patients treated for multidrug-resistant tuberculosis? Int J Tuberc Lung Dis 2019;23:1060-7.

40. WHO. Rapid communication: key changes to treatment of drugresistant tuberculosis. Geneva: World Health Organization; 2019.

41. TB Alliance [Internet]. FDA approves new treatment for highly drug-resistant forms of tuberculosis. Accessed on: 28 September 2019. Available from: https://www.tballiance.org/ news/fda-approves-new-treatment-highly-drug-resistantforms-tuberculosis. 